\title{
Application of Computational Fluid Dynamics in Atmospheric Environment Simulation: a Case Study in Shenyang, China
}

\author{
Zhou Yuan ${ }^{1, a^{*}}$ \\ ${ }^{1}$ Architecture and urban planning college, southwest university for nationalities, \\ \#16, South Section, 1st Ring Road, Chengdu, Sichuan, China, Post Code 610041 \\ azhouyuan840205@163.com
}

Keywords: Atmospheric environment, Numerical simulation, Computational fluid dynamics, Shenyang

\begin{abstract}
Atmospheric environment simulation in urban space plays an important role in the improvement of urban air problems and the sustainable development of the city. Using Remote Sensing (RS) and the spatial analysis technology in Geographic Information System (GIS), combined with the numerical simulation technology of Computational Fluid Dynamics (CFD) model, this study simulated $\mathrm{SO}_{2}$, wind and temperature of Shenyang city under the influence of current urban landscape pattern in summer so as to analyze the spatial diffusion of $\mathrm{SO}_{2}$, wind speed and temperature in different height. The results showed that: 1) The spatial diffusion of $\mathrm{SO}_{2}$, urban wind speed and temperature had closely related to urban spatial layouts such as the layout of building and urban green space. 2) Urban heat island effect was obvious in the areas with high building density and high population density because the internal wind speed was lower, and $\mathrm{SO}_{2}$ concentration was not easily spread out. Urban green spaces and water bodies had significant roles in alleviating urban heat island effect and improving air quality. 3) As influenced by wind speed and direction, the spatial spread resistance on $\mathrm{SO}_{2}$ and temperature was gradually reduced along with height increasing. 4) At present, because of lacking good ventilation corridor coupled with high density of urban construction, urban ventilation and the operating conditions of urban thermal environment are poor, $\mathrm{SO}_{2}$ pollution is serious in Shenyang city. The diffusion simulation of atmospheric environment factors based on CFD can effectively find the existing problems of urban green space layout in Shenyang city, and provide a new method for the quantitative planning of urban green space optimization pattern.
\end{abstract}

\section{Introduction}

With the rapid growth of urban population and the constant enlargement of city scale, urban impervious surface area was increased, the environmental problems include serious air pollution, urban heat island effect, lacking of climate adaptability were highlighted, and these problems are closely related to atmospheric environment factors (such as $\mathrm{SO}_{2}$, wind, temperature). Green space is an important part of urban ecological system, the reasonable planning of green space has an important role in improving urban air pollution problems and the sustainable development of the city. The landscape pattern of urban green space has great effect on $\mathrm{SO}_{2}$ diffusion, wind environment, urban thermal environment [1-3]. At present, most of the urban green spaces are occupied, green space area is reduced or fragmentation serious [4], the ecological connectivity of green space is low, and there is no effective green space network structure to form. In the limited urban space, how to construct the optimization layout of urban green space to alleviate the contradiction between air pollution problems and urban construction, has become a hot issue of urban planners.

Computational Fluid dynamics (CFD) model is an effective technique for fluid material motion simulation, which is applicable to all kinds of heat transfer and fluid material flow problems. At present, many scholars have used CFD to simulate the relationship between the atmospheric environment and urban planning, such as the influence of road structure, street canyon and architectural shape factors on air pollutants dispersion, the research of operating condition of urban 
wind environment and urban thermal environment [5-7], but using CFD to simulate atmospheric environment factors under the influence of green space landscape pattern have less involved. In the process of green space landscape pattern planning, we should consider the dispersion of atmospheric environment factors, qualitative and quantitative study the planning of urban green space spatial pattern by using various technical means, and improve the ecological function of urban green space. Therefore, using RS and GIS, combined with CFD numerical simulation technology, this study simulated atmospheric environment factors of Shenyang city under the influence of current green space landscape pattern in summer to analyze the spatial diffusion of $\mathrm{SO}_{2}$, wind speed and urban temperature in different height, so as to find the problems of current green space layout in Shenyang, which provide a new method for quantitative planning urban green space system.

\section{Experimental}

Materials. The atmospheric environment factors of this study are $\mathrm{SO}_{2}$, wind, temperature. In order to obtain $\mathrm{SO}_{2}$ concentration in different regions of the city, according to the principle of representative, convenience, 78 points which respectively located in specific industrial zone, general industrial area, commercial area, residential area, cultural area and clean area in Shenyang city were selected to field monitor $\mathrm{SO}_{2}$ concentration, at the same time, urban wind speed and temperature in these points were also field monitored. Monitoring time was selected in the plant growth season (August 14, 2010 to August 29,2010) and the daytime which have a greater impact on the people public work and life. The temperature and wind speed were measured every $2 \mathrm{~h}$ time interval from 8:00 to 17:00, which repeated 5 days. The atmospheric $\mathrm{SO}_{2}$ content was sampled and analyzed form 14:00 to 15:00 using the KZL type portable $\mathrm{SO}_{2}$ monitor to obtain $\mathrm{SO}_{2}$ monitoring data in different land type.

Methods. In this paper, by using CFD to simulate atmospheric environment factors under the influence of current urban landscape pattern in Shenyang city. Its working process include in establishing digital model, setting up boundary conditions, model operation calculation and results analysis [5].

Firstly, by means of RS and spatial analysis techniques of GIS, on the basis of comprehensive analysis in urban building density, vegetation coverage degree, plot ratio, urban heat island effect, $\mathrm{SO}_{2}$ level, population density, Shenyang digital module was established on the scale of 1: 1 which in the zoom of $50000 \mathrm{~m} * 50000 \mathrm{~m} * 200 \mathrm{~m}$.

Secondly, boundary conditions setting: after model was created in CFD, we can input initial conditions of the simulation, including the longitude and latitude of simulation urban, computational time, parameters such as incident angle related to the sun radiation, air refractive index. Setting the mixed laminar flow model to simulate the atmospheric flow and choosing thermal radiation model and pollutant diffusion model for model blocks. Setting the initial temperature and $\mathrm{SO}_{2}$ concentration of different modules based on the field monitoring and interpolation analysis. Setting the wind speed parameters such as wind speed in different position of inlet and outlet. Taking Shenyang as an example, the simulation of climatic conditions was set for summer, the average wind speed was $3 \mathrm{~m} / \mathrm{s}$, the dominant wind direction was south, the initial parameters in the inlet and outlet of simulation boundary were set for the concrete temperature and the wind speed values, to simulate the climate and environment impact on the digital city model in this period $[8,9]$.

Thirdly, the model operation calculations: model calculation mainly through the division of grid, model operations, convergence and other steps to complete. It will simulate the spatial operation condition of factors such as $\mathrm{SO}_{2}$, urban wind speed, temperature.

Fourthly, the calculation results analysis: after completing the calculation, the results can be carried out in accordance with the numerical display of $\mathrm{SO}_{2}$, wind speed, temperature and other factors. According to the height and position of the model, the numerical display diagram of the horizontal and vertical profiles can be choosing. 


\section{Results}

With height increasing, urban building density and plot ratio were decreased, the spatial diffusion resistance of urban wind speed, $\mathrm{SO}_{2}$ and temperature were reduced, spatial diffusion resistance were inversely proportional to the diffusion height. In the range of $0 \sim 200 \mathrm{~m}$, the height range of $0 \sim 10 \mathrm{~m}$ (including $10 \mathrm{~m}$ ) is defined as the bottom effect field, and the height range from 10 to $50 \mathrm{~m}$ (including $50 \mathrm{~m}$ ) is the middle effect field and the height range of $50 \mathrm{~m}$ to $200 \mathrm{~m}$ is the top effect field.

$\mathrm{SO}_{2}$ Simulation Analysis in Different Heights. From the simulation analysis diagram of $\mathrm{SO}_{2}$ in different vertical height (Fig. 1), we can see that the concentration of $\mathrm{SO}_{2}$ was gradually decreased with the increase of wind speed at the height of $1.5 \mathrm{~m}$. In Dadong District, Tiexi District, Yuhong District of Shenyang city, industrial pollution sources were more, urban green spaces were less, $\mathrm{SO}_{2}$ concentration was the highest and which was not easy to spread outward. Shenhe District, Heping District with high population density, high buildings density, which located in the city center area, $\mathrm{SO}_{2}$ concentration was relatively higher. For the whole building in the city, $\mathrm{SO}_{2}$ concentration in the windward side was lower than the leeward side. With height increasing, the influence of building on $\mathrm{SO}_{2}$ concentration field distribution was gradually weakened, the specific performance is: on the one hand, the bottom of $\mathrm{SO}_{2}$ concentration field had the most concentration difference, the middle take second place, and the minimum the top had. On the other hand, the highest concentration also appeared in the bottom $\mathrm{SO}_{2}$ concentration field, the maximum concentration at the top $\mathrm{SO}_{2}$ concentration field was less than the bottom and the middle.
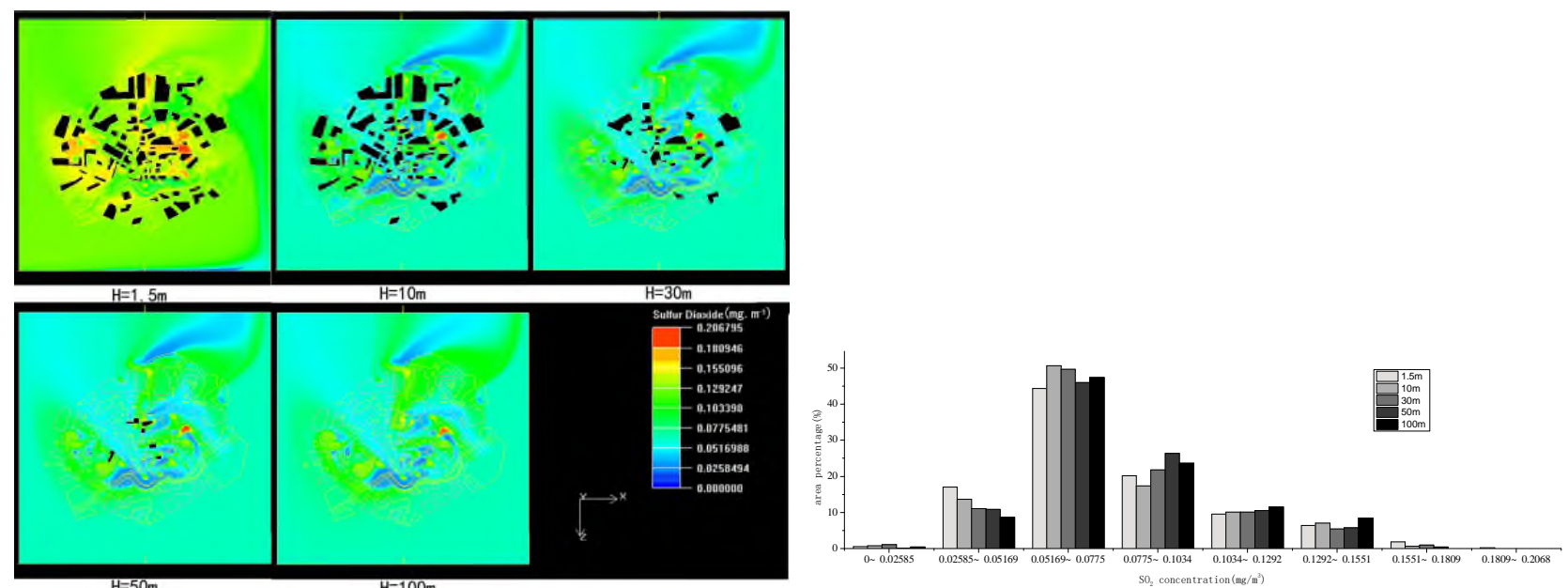

Fig. 1 The $\mathrm{SO}_{2}$ diffusion simulation of urban different height and the $\mathrm{SO}_{2}$ contrast analysis of different height in Shenyang city.

With the increase of the height, the higher $\mathrm{SO}_{2}$ concentration was mainly distributed in the area of Dadong District and Tiexi District and had no change. At the bottom concentration field of $1.5 \mathrm{~m}$, the concentration value was concentrated in the $0.05169-0.0775 \mathrm{mg} / \mathrm{m}^{3}$. As the height increased, at the middle concentration field, the maximum concentration value was $0.1809 \mathrm{mg} / \mathrm{m}^{3}$, and at the top concentration field up to $100 \mathrm{~m}$, the maximum concentration value was $0.1551 \mathrm{mg} / \mathrm{m}^{3}$.

Urban Wind Speed Simulation Analysis in Different Heights. From the simulation analysis diagram of urban wind in different vertical height (Fig. 2), we can see that wind speed was significantly affected by urban building layout and urban wind flow at the height of $1.5 \mathrm{~m}$. In the low urban building density areas such as Hunnan New District, Yuhong District, urban wind speed was relatively higher, urban ventilation corridor had formed along the river which good for surrounding pollutant diffusion and alleviating urban heat island effect. In Shenhe District, Heping District, Tiexi District, Huanggu District and other areas with higher urban building density, urban wind speed was relatively lower. The horizontal diffusion of urban wind environment was closely related to urban buildings density. In the area of urban high building density, the wind speed was low and the area ratio of static wind area was very high. At the bottom $(1.5 \mathrm{~m}, 10 \mathrm{~m})$ and the middle $(30 \mathrm{~m}$ and $50 \mathrm{~m})$ wind 
velocity fields, the wind speed of the windward side was greater than the leeward side, and at the top $(100 \mathrm{~m})$ velocity field, velocity field distribution was relatively uniform. Therefore, the size of the velocity value is mainly determined by the height of urban building. The higher the building, the greater the wind velocity value of the corresponding area, and its spatial diffusion resistance is decreased.

At the bottom wind velocity field up to $1.5 \mathrm{~m}$, urban wind was worked at low wind speed, and the area ratio of $2.625-3 \mathrm{~m} / \mathrm{s}$ wind speed was only $7.13 \%$. Along with the increase of the height, at the bottom wind velocity field up to $10 \mathrm{~m}$, breeze area was cut down, the area ratio of $2.625-3 \mathrm{~m} / \mathrm{s}$ wind speed was increased to $23.38 \%$. With the height increasing, the area ratio of $2.625-3 \mathrm{~m} / \mathrm{s}$ wind speed showed a trend of gradually increasing, but the increasing area was relatively flat. Therefore, it can be inferred that urban wind speed is closely related to the height. Building density is decreased when building height increasing, wind speed is gradually increased, and the impact of building on the urban wind speed is also gradually decreased.
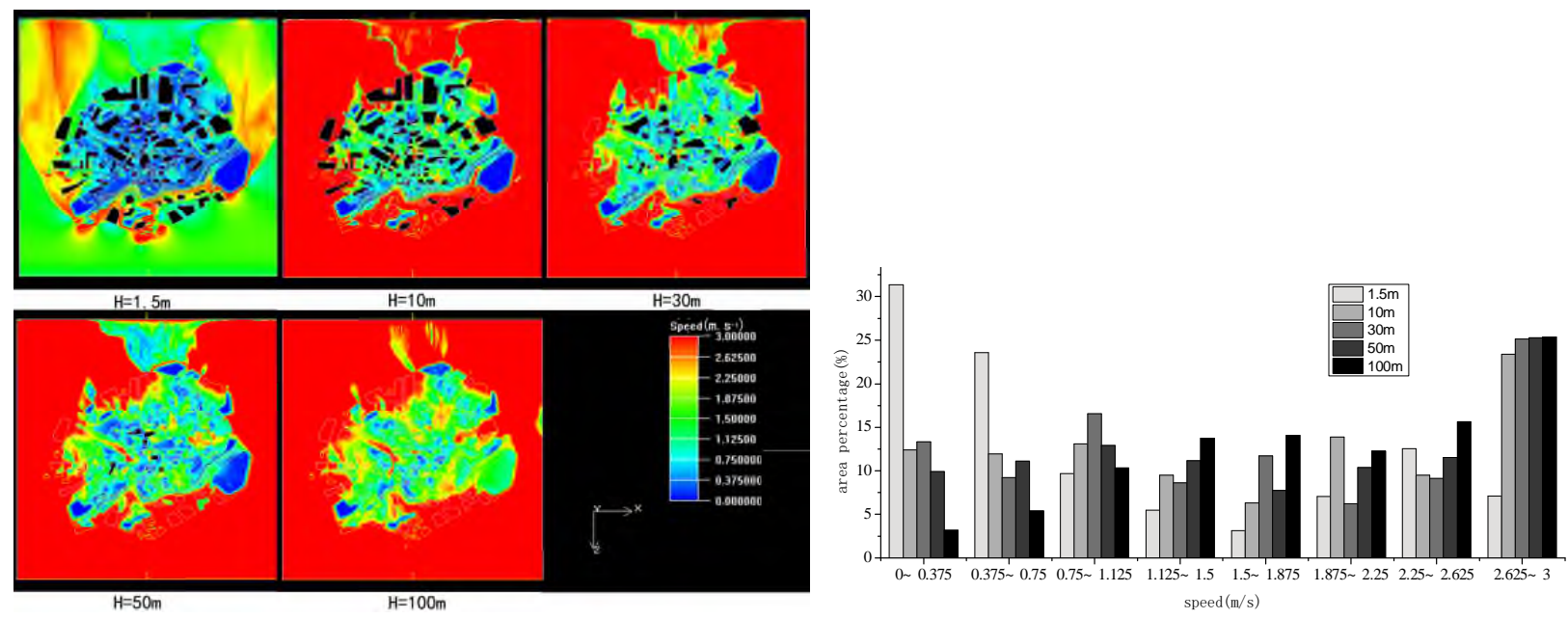

Fig. 2 The speed diffusion simulation of urban different height and the speed contrast analysis of different height in Shenyang city.
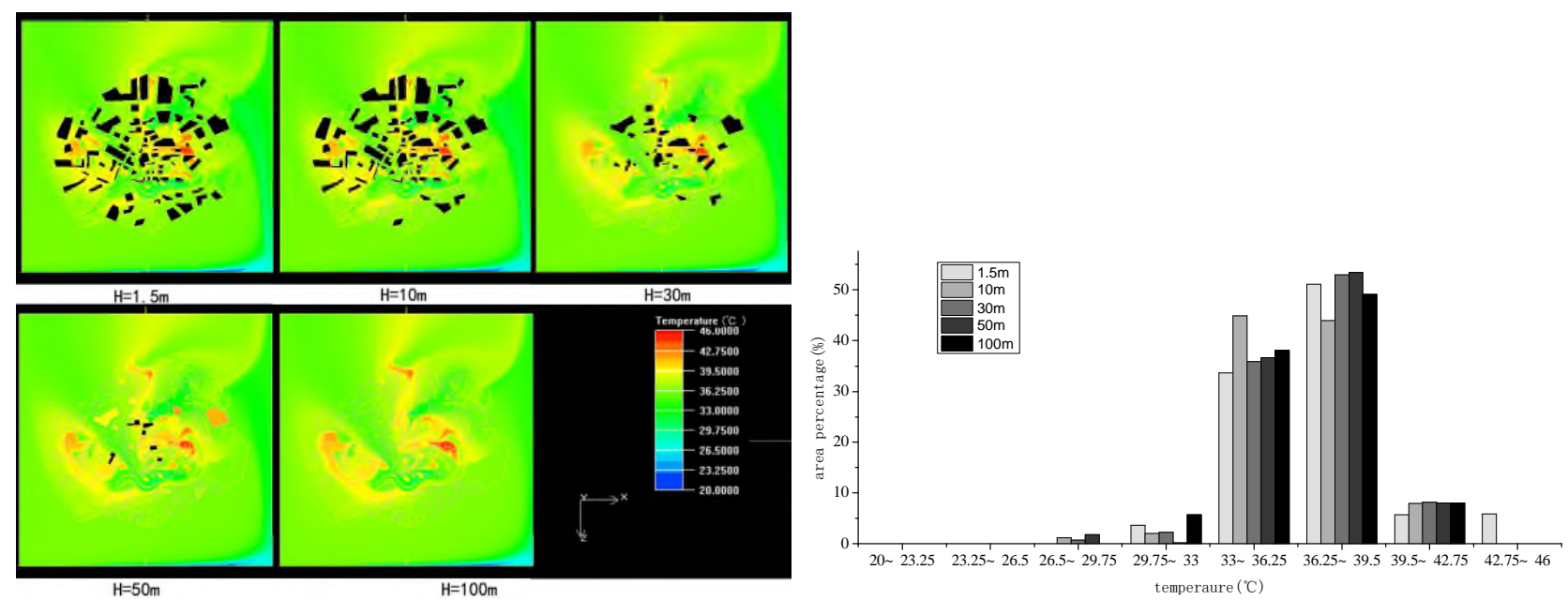

Fig. 3 The temperature of urban different height and the temperature contrast analysis of different height in Shenyang city.

Temperature Simulation Analysis in Different Heights. From the simulation analysis diagram of urban temperature in different vertical height (Fig. 3), we can see that the average temperature was $37^{\circ} \mathrm{C}$ in Shenyang at the height of $1.5 \mathrm{~m}$. The temperature was up to $40^{\circ} \mathrm{C}$ in the high building density areas such as business street, residence, industry, large transportation hubs, and the temperature was relatively low in the school, green space, water etc, which had an important significance to relieve 
urban heat island effect. Urban water bodies being upwind can take the lower temperature air into the city, but the wind velocity was decreased obviously after the wind blowing over the city. Wind circulation was very slow especially in the inner city because building in the city had a larger block on the air circulation. Urban wind, vegetation and water which improved the temperature condition of hottest areas in city were relatively limited because of lacking reasonable urban planning, and the effect of water, vegetation and other natural areas did not better play out.

With height increasing, the diffusion resistance of building on the temperature field distribution was gradually weakened, but the areas which urban heat island effect was obvious did not significantly decrease, and mainly concentrated in Tiexi District, Dadong District, Huanggu District. With similar as $\mathrm{SO}_{2}$ and urban wind speed diffusion rules, the highest temperature difference was at the bottom temperature field, the middle temperature field was the second and the top was the least. At the bottom temperature field of $1.5 \mathrm{~m}$, the temperature value was concentrated in $33-39.5^{\circ} \mathrm{C}$; With height increasing, at the middle temperature field, although the temperature values was also focused on $33-39.5^{\circ} \mathrm{C}$, but the highest temperature value was declined, which between 39.5 to $42.75^{\circ} \mathrm{C}$; at the top temperature field up to $100 \mathrm{~m}$, the highest temperature value was between $39.5^{\circ} \mathrm{C}$ to $42.75^{\circ} \mathrm{C}$, and the area ratio was relatively lower than other heights.

Through the comprehensive analysis of $\mathrm{SO}_{2}$, wind and temperature diffusion diagram we can see that the main factors affecting urban environmental problems included the spatial layout of urban green space, urban building height, building density, population density etc. At present, because of lacking good ventilation corridor, coupled with high building density, there had more environmental problems in Shenyang such as poor urban ventilation, poor thermal environment condition, seriously $\mathrm{SO}_{2}$ pollution, especially in Tiexi District, Dadong District, Huanggu District. In other areas, urban heat island effect was not very obvious mainly because the green coverage rate of this region was relatively high, such as Hun river had a significant role in improving urban heat island effect. In the optimization of green space landscape pattern, we need to take the advantages of CFD to analyze the internal mechanism relationship between urban green space, water and urban structure from the angle of atmospheric environment dynamic flow, and carry out conceptual design, in addition to need to put forward the optimization measures and simulation, such as constructing urban ventilation corridors to improve the urban air problems.

CFD Model Validation. Many scholars had verified CFD simulation accuracy $[5,10]$. In this study, in order to validate the numerical simulation accuracy, CFD simulation results and the measured values were compared and analyzed, and correlation analysis was used to verify the relationship between them. The results showed that the relative error between the simulated and measured values was small, and it can meet the accuracy of urban scale model simulation [9]. The CFD model is effective and feasible to simulate the atmospheric environment.

\section{Summary}

This study simulated atmospheric environment factors (such as $\mathrm{SO}_{2}$, wind, temperature)of Shenyang city in summer by using CFD simulation technology to analyze urban environment problems under the influence of urban current green space landscape pattern. The analysis was completed mainly through the three-dimensional spatial diffusion results of $\mathrm{SO}_{2}$, wind speed and temperature. From the simulation analysis diagram of $\mathrm{SO}_{2}$, wind speed and temperature in different vertical height, we can see that urban spatial layout (such as green spaces, building density, plot ratio) had a manifest influence on the spatial diffusion of $\mathrm{SO}_{2}$, urban wind speed and temperature. Both $\mathrm{SO}_{2}$, urban wind speed or temperature, the highest difference was at the bottom effect field, the middle effect field was the second and the top was the least, and the highest value also appeared in the bottom effect field, the maximum value at the top effect field was less than the bottom and the middle. For the whole building group in city, the diffusion resistance of building on $\mathrm{SO}_{2}$, urban wind speed and temperature was weakened gradually with the increase of height. It not only provides a new idea for urban green space system quantitative planning and green space layout optimization through dynamic 
simulating atmospheric environment running status by CFD, but also has an important role in improving the urban ecological environment problems.

\section{Acknowledgment}

This research was sponsored by National Natural Science Found Project of China (51508483); Fundamental basic scientific of Central Universities in southwest university for nationalities (2015NZYQN03).The author is grateful to all members who participated in the project.

\section{References}

[1] F. Li, R. S. Wang, J. Paulussen, et al. Comprehensive concept planning of urban greening based on ecological principles: a case study in Beijing, China, Landsc. Urban Plan. 72(4) (2005) 325-336.

[2] M. M. Mcconnachie, M. C. Shackleton, Public green space inequality in small towns in South Africa, Habitat Int. 34(2) (2010) 244-248.

[3] D. Govindarajulu, Urban green space planning for climate adaptation in Indian cities, Urban Clim. 10 (2014) 35-41.

[4] F. H. Kong, H. W. Yin, N. Nakagoshi, et al. Urban green space network development for biodiversity conservation: Identification based on graph theory and gravity modeling, Landsc. Urban Plan. 95(1-2) (2010) 16-27.

[5] H. Huang, R. Ookaa, H. Chen, et al. CFD analysis on traffic-induced air pollutant dispersion under non-isothermal condition in a complex urban area in winter, J. wind Eng. Ind. Aerodynamics, 96(10-11) (2008) 1774-1788.

[6] Y. Zhou, T. M. Shi, Y. M. Hu, et al. Urban green space planning based on computational fluid dynamics model and landscape ecology principle: a case study of Liaoyang city, northeast China, Chin. Geogr. Sci. 21(4) (2011) 1-11.

[7] J. H. Amorim, V. Rodrigues, R. Tavares, et al. CFD modelling of the aerodynamic effect of tree on urban air pollution dispersion, Sci. Total Environ. 461-462c (2013), 541-551.

[8] K. Li, City Heat Environment research based on remote Sensing and CFD simulation-a case study of Wuhan city in summer, Huazhong University, Wuhan, 2008.

[9] Y. Zhou, T. M. Shi, Y. M. Hu, et al. Study on green space landscape pattern optimization based on urban climatic environment features, Urban plan. 38 (2014) 83-89.

[10]X. X. Li, C. H Liu, Y. C. Dennis, et al. Recent progress in CFD modelling of wind field and pollutant transport in street canyons, Atmos. Environ. 40(29) (2006) 5640-5658. 